'Departamento de Ciências Agrărias, Universidade Estadual de Montes Claros (Unimontes), Campus Janaúba, Av. Reinaldo Viana, 2630, Bico da Pedra, CEP 39440-000, Janaúba, MG, Brasil

${ }^{2}$ Departamento de Fitotecnia, Universidade Federal de Viçosa (UFV), Viçosa, MG, Brasil.

* autor correspondente 凶htiagoamaro@yahoo.com.br

\section{Bioestimulante e umidade do substrato no desempenho fisiológico de sementes de algodão}

\author{
Biostimulant and substrate moisture on physiological \\ performance of cotton seeds
}

Rodrigo César Carvalho Antunes ${ }^{1}$, Andréia Márcia Santos de Souza David', Hugo Tiago Ribeiro Amaro²* Vitória Serafim Oliveira' ${ }^{1}$, Miquéias de Oliveira Assis², Dorismar David Alves ${ }^{1}$
RESUMO: O uso de biorreguladores vegetais vem proporcionando efeitos positivos no rendimento de diversas culturas. Dessa forma, o objetivo do trabalho foi avaliar o efeito de bioestimulante e umidade do substrato no desempenho fisiológico de sementes de algodão. Utilizaram-se sementes de algodão cultivar FMX 966, deslintadas quimicamente e tratadas com o bioestimulante Stimulate ${ }^{\circledR}$ nas seguintes concentrações: 0,0 (testemunha); 5,0; 10,0; 15,0; e 20,0 $\mathrm{mL} \mathrm{kg}^{-1}$ de sementes, variando na umidade do substrato $30 \mathrm{e}$ $60 \%$ da sua capacidade de retenção. Utilizou-se o delineamento experimental inteiramente casualizado, em arranjo fatorial $5 \times 2$, (cinco doses do bioestimulante e duas umidades do substrato), constituindo em dez tratamentos e quatro repetições. A qualidade fisiológica das sementes foi avaliada pelos seguintes testes e/ ou determinações: teor de água, emergência de plântulas, índice de velocidade de emergência, comprimento de parte aérea, comprimento de raiz, matéria fresca e matéria seca de parte aérea. O bioestimulante Stimulate ${ }^{\circledR}$ aplicado via sementes não influencia o desempenho fisiológico de sementes de algodão cultivar FMX 966, apenas o comprimento de raiz é influenciado pelas condições de umidade do substrato.

PALAVRAS-CHAVE: Gossypium hirsutum, reguladores de crescimento, testes de vigor.
ABSTRACT: The use of plant bioregulators has provided contribution to the performance of diverse cultures. Thus, the objective of the work was to evaluate the effect of bio stimulant and humidity of the substrate on the physiological performance of cotton seeds. Were used cultivar cotton seed FMX 966, delinted and chemically treated with biostimulant Stimulate ${ }^{\circledR}$ in the following concentrations: 0.0 (control); 5.0; 10.0; 15.0; and $20.0 \mathrm{~mL} . \mathrm{kg}^{-1}$ of seed, ranging in substrate humidity 30 and $60 \%$ of its holding capacity. We used a completely randomized design in a factorial $5 \times 2$ (five doses of the growth promoter and two humidity of the substrate), constituting ten treatments and four replications. The physiological seed quality was evaluated by the following tests and/or parameters: water content, seedling emergence, emergence speed index, shoot length, root length, fresh and dry matter of shoots. The biostimulating Stimulate ${ }^{\circledR}$ applied to seeds does not influence the physiological performance of cotton seeds cultivar FMX 966, only the root length is influenced by the moisture conditions of the substrate.

KEYWORDS: Gossypium hirsutum, growth regulators, vigor tests.
O algodão (Gossypium hirsutum L.) produzido por mais de 60 países, nos cinco continentes, está entre as mais importantes culturas de fibras no mundo. Resultados da ultimas três safras, com volume médio de 1,7 milhões de toneladas de pluma, colocaram o Brasil entre os cinco maiores produtores mundiais, além de ser também o terceiro país exportador e o primeiro em produtividade em sequeiro (ASSOCIAÇÃO..., 2014). 
Os agricultores têm exigido, cada vez mais, sementes de alta qualidade, que possibilitem uma emergência mais rápida e um estande uniforme no campo (LAUXEN; VILLELA; SOARES, 2010). O uso de reguladores vegetais na fase de germinação melhora o desempenho das plântulas, acelerando a velocidade de emergência e realçando o potencial das sementes de várias espécies (ARAGÃO; DANTAS; ALVES, 2003).

Os biorreguladores vegetais são substâncias sintetizadas que, aplicadas exogenamente, possuem ações similares à dos grupos de fitormônios conhecidos (VIEIRA; CASTRO, 2002), os quais promovem, inibem ou modificam processos fisiológicos e morfológicos do vegetal (VIEIRA; CASTRO, 2001).

O emprego de novos produtos para a incorporação de aditivos às sementes aumenta a cada ano, podendo trazer benefícios como a melhoria do desempenho das plântulas. A principal característica do tratamento de sementes é a aplicação de pequenas doses de produtos com elevada precisão, contribuindo para a redução de custos e produtos químicos lançados ao meio ambiente (ALBUQUERQUE et al., 2009).

Os resultados de pesquisas são contraditórios. Santos e Vieira (2005) comprovaram que determinado bioestimulante, aplicado via sementes, é capaz de originar plântulas de algodoeiro mais vigorosas. No entanto, Silva et al. (2008) avaliando o efeito dos bioestimulantes Stimulate ${ }^{\circledR}$; Cellerate $^{\circledR}$ e Booster ${ }^{\circledR}$, observaram que não houve melhoria da qualidade de sementes quando elas foram submetidas a tratamento com bioestimulantes.

O algodoeiro se caracteriza como uma planta de crescimento inicial lento, sendo uma cultura extremamente sensível ao déficit hídrico. De acordo com Carvalho e Nakagawa (2012), existe um teor mínimo de água disponível para que ocorra a completa reidratação da semente, do contrário, sem umidade adequada a lavoura não encontrará condições para se estabelecer. Alguns trabalhos têm mostrado resultados na melhoria da resistência das plantas ao estresse hídrico, quando são submetidas à aplicação de produtos a base de biorreguladores, uma vez que os níveis das atividades de enzimas envolvidas no processo germinativo, de maneira geral, aumentam com o uso de bioestimulantes (ZHANG; ERVIN, 2004).

Diante do exposto, o objetivo do presente trabalho foi avaliar o efeito de bioestimulante Stimulate ${ }^{\circledR}$ e da umidade do substrato no desempenho fisiológico de sementes de algodão.

Para a realização do experimento, utilizaram-se sementes de algodão cv. FMX 966, deslintadas quimicamente, e produzidas na região oeste do Estado da Bahia, colhidas em setembro de 2011. O experimento foi conduzido no Laboratório de Análise de Sementes do Departamento de Ciências Agrárias da Universidade Estadual de Montes Claros (DCA/UNIMONTES), Campus Janaúba, nos meses de março a abril de 2012.

As sementes foram tratadas com o fungicida Thiram na concentração de $0,5 \%$ (500 $\mathrm{mL}$ do fungicida para $100 \mathrm{~kg}$ de sementes) e posteriormente foi aplicado o bioestimulante Stimulate ${ }^{\circledR}$, nas concentrações: 0,$0 ; 5,0 ; 10,0$; 15,0 e $20,0 \mathrm{~mL} \mathrm{~kg}^{-1}$ de sementes, com o auxílio de uma pipeta graduada diretamente sobre as sementes, sendo acondicionadas em sacos plásticos transparentes com capacidade de $5,0 \mathrm{~kg}$. Após a aplicação do produto, os sacos contendo as sementes foram inflados com ar e agitados vigorosamente durante cinco minutos, visando uniformizar a distribuição dos tratamentos sobre toda a massa de sementes. Em seguida, as sementes tratadas foram colocadas para secar a sombra.

De acordo com a recomendação das Regras de Análise de Sementes - RAS (BRASIL, 2009), deve-se umedecer o substrato com $60 \%$ da sua capacidade de retenção durante as análises. A fim de testar a umidade do substrato durante a realização do experimento, utilizou-se 30 e $60 \%$ da capacidade de retenção de água no substrato, com o objetivo de simular um estresse hídrico à cultura do algodoeiro. A avaliação da qualidade fisiológica das sementes foi determinada por meio dos testes e determinações descritos a seguir.

$\mathrm{O}$ teor de água das sementes foi determinado conforme metodologia prescrita nas RAS (BRASIL, 2009), utilizando-se o método da estufa, a $105 \pm 3{ }^{\circ} \mathrm{C}$, durante 24 horas, com quatro repetições de 50 sementes, sendo os resultados expressos em porcentagem de umidade.

O teste de emergência de plântulas foi conduzido sob condições ambientais controladas de laboratório, com temperatura média de $25{ }^{\circ} \mathrm{C}$ e regime luminoso de 12 horas de luz. As sementes foram semeadas em bandejas plásticas contendo areia lavada e esterilizada, a $2 \mathrm{~cm}$ de profundidade, umedecida a 30 e $60 \%$ da capacidade de retenção. Foram utilizadas quatro repetições de 50 sementes por tratamento e os resultados foram obtidos pelo número de plântulas normais emersas, determinado por ocasião do décimo segundo dia após a montagem do experimento (BRASIL, 2009).

$O$ índice de velocidade de emergência foi conduzido em conjunto com teste de emergência em areia, anotando-se diariamente, no mesmo horário, o número de plântulas que apresentaram alça cotiledonar visível. Ao final do teste, com os dados diários do número de plântulas emergidas, foi calculado o índice de velocidade de emergência, empregando-se a fórmula proposta por Maguire (1962). IVE=E1/N1 + E2/ $\mathrm{N} 2+\ldots+\mathrm{En} / \mathrm{Nn}$, sendo: IVE = Índice de velocidade de emergência; E1, E2, ..., En = número de plântula emergidas no dia, computadas na primeira, segunda, ..., última contagem; $\mathrm{N} 1, \mathrm{~N} 2, \ldots, \mathrm{Nn}=$ número de dias da semeadura à primeira, segunda, ..., última contagem.

No final do teste de emergência de plântulas foi determinado o comprimento da parte aérea e de raízes das plântulas consideradas normais, sendo os resultados expressos em comprimento médio da plântula $(\mathrm{cm})$.

A massa de matéria fresca $(\mathrm{g})$ de parte aérea foi determinada utilizando as plântulas normais de cada tratamento, sendo pesadas em balança de precisão. Em seguida, analisou-se a massa seca da parte aérea $(\mathrm{g})$ as mostras foram colocadas em sacos de papel e levadas para secar em estufa com circulação forçada de ar, a $65{ }^{\circ} \mathrm{C}$ constante, durante 72 horas. Após este período, as amostras foram colocadas para resfriar no dessecador e novamente pesadas para obtenção do peso da matéria seca, com resultados expressos em g. 
Utilizou-se o delineamento experimental inteiramente casualizado, em arranjo fatorial $5 \times 2$, envolvendo cinco doses do bioestimulante Stimulate ${ }^{\circledR}(0,0 ; 5,0 ; 10,0 ; 15,0$ e $20,0 \mathrm{~mL}$ $\mathrm{kg}^{-1}$ de sementes) e duas umidades do substrato (30 e $60 \%$ da capacidade de retenção).

Para a avaliação dos dados foi o utilizado o programa Sistema de Análises Estatísticas e Genéticas (UNIVERSIDADE..., 2007). Os resultados foram submetidos à análise de variância e para as médias dos tratamentos foram ajustadas equações de regressão polinomial em nível de 5\% pelo teste "F".

Os valores médios dos teores de água das sementes de algodão, como procedimento inicial na realização das análises, indicaram que as mesmas apresentavam com $10 \%$ de umidade.

A interação entre os fatores umidades do substrato e doses de bioestimulante não foi significativa para as variáveis emergência de plântulas (EP), índice de velocidade de emergência (IVE), comprimento radicular (CR), comprimento de plântulas (CP), massa fresca (MF) e massa seca (MS). O efeito de doses de bioestimulante não foi significativo para nenhuma das variáveis. Exceto o comprimento de raiz, as demais variáveis não foram afetadas de modo significativo pelas umidades de substrato (Tabela 1).

$\mathrm{O}$ bioestimulante não afetou o vigor das sementes de algodão nas dosagens utilizadas (Tabela 2). Provavelmente o tempo de exposição das sementes ao bioestimulante pode não ter sido suficiente para promover incrementos significativos na qualidade fisiológica das sementes. Nesse sentido, a quantidade de fitormônios absorvida depende fundamentalmente da superfície de contato da semente, da quantidade de água e da concentração da solução, contendo os biorreguladores, absorvida pelas sementes (BUCHANAN; GRUISSEM; JONES, 2000). Assim, a menor absorção do regulador de crescimento pode ter comprometido sua eficiência no vigor das sementes. Moterle et al. (2011) ressaltam que a absorção dos hormônios pode variar entre diferentes cultivares, provavelmente por diferenças morfogênicas e/ou taxas de absorção diferenciadas do biorregulador.

Observa-se por meio do teste de emergência de plântulas, que houve uma variação de 88 (tratamentos controle e $5 \mathrm{~mL} \mathrm{~kg}^{-1}$ de bioestimulante) a $92 \%$ (15 e $20 \mathrm{~mL} \mathrm{~kg}^{-1} \mathrm{de}$ bioestimulante) de plântulas emersas (Tabela 2). Vale ressaltar que os valores observados no presente trabalho estão acima do padrão mínimo exigido para produção e comercialização para todas as categorias de sementes de algodão (BRASIL, 2005).

Analisando isoladamente a fonte de variação umidade do substrato, observou-se um incremento de $1,31 \mathrm{~cm}$ no comprimento de raízes das plântulas de algodão quando essas foram semeadas em substrato contendo apenas $30 \%$ da sua capacidade de retenção (Tabela 3). A habilidade no crescimento das raízes em níveis de potencial hídrico muito baixo é uma característica de plantas não domesticadas, que permaneceram nos genótipos melhorados (ECHER et al., 2010). O fato de essas plantas permanecerem crescendo é devido à capacidade que possuem de manterem os tecidos mais hidratados que o meio circundante, seja por ajustamento osmótico, ou por manterem os estômatos fechados por um maior tempo, reduzindo a perda

Tabela 1. Resumo da análise de variância para as variáveis, emergência de plântulas (EP), índice de velocidade de emergência (IVE), comprimento de raiz (CR), comprimento de parte aérea (CP), massa fresca da parte aérea (MF) e massa seca da parte aérea (MS) de plântulas de algodão (Gossypium hirsutum L.).

\begin{tabular}{|c|c|c|c|c|c|c|c|}
\hline \multirow{2}{*}{ Fontes variação } & \multirow{2}{*}{ GL } & \multicolumn{4}{|c|}{ Quadrados Médios } & \multirow{2}{*}{ MF } & \multirow{2}{*}{ MS } \\
\hline & & EP & IVE & CR & $\mathbf{C P}$ & & \\
\hline Doses bioes. (D) & 4 & $32,60^{\mathrm{ns}}$ & $8,56^{\mathrm{ns}}$ & $5,04^{\mathrm{ns}}$ & $0,86^{\mathrm{ns}}$ & $3,18^{\mathrm{ns}}$ & $0,13^{\text {ns }}$ \\
\hline Umidade sub. (U) & 1 & $6,40^{\mathrm{ns}}$ & $12,15^{\text {ns }}$ & $19,29 *$ & $0,50^{\mathrm{ns}}$ & $42,02^{\mathrm{ns}}$ & $0,03^{\text {ns }}$ \\
\hline DXU & 4 & $69,40^{\text {ns }}$ & $5,98^{\mathrm{ns}}$ & $5,07^{\mathrm{ns}}$ & $0,98^{\mathrm{ns}}$ & $6,90^{\mathrm{ns}}$ & $0,06^{\mathrm{ns}}$ \\
\hline Resíduo & 30 & 47,93 & 7,89 & 3,90 & $0,79^{\text {ns }}$ & $11,26^{\mathrm{ns}}$ & $0,09^{\text {ns }}$ \\
\hline \multicolumn{2}{|c|}{$\mathrm{CV} \%$} & 7,67 & 14,67 & 19,39 & 11,17 & 16,09 & 17,09 \\
\hline
\end{tabular}

${ }^{\mathrm{ns}}$ não significativo; * significativo à $5 \%$ de probabilidade pelo teste $\mathrm{F}$.

Tabela 2. Resultados de emergência de plântulas (EP), índice de velocidade de emergência (IVE), comprimento de raiz (CR), comprimento de parte aérea (CP), massa fresca da parte aérea (MF) e massa seca da parte aérea (MS), em função das doses de bioestimulante Stimulate ${ }^{\circledR}$, aplicado via sementes de algodão (Gossypium hirsutum L.).

\begin{tabular}{|c|c|c|c|c|c|c|}
\hline \multirow{2}{*}{ Variável } & \multicolumn{5}{|c|}{ Doses de bioestimulante $\left(\mathrm{mL} \mathrm{kg} \mathbf{~}^{-1}\right)$} & \multirow{2}{*}{$\mathbf{y}$} \\
\hline & $\mathbf{0}$ & 5 & 10 & 15 & 20 & \\
\hline $\mathrm{EP}(\%)$ & 88 & 88 & 90 & 92 & 92 & 90 \\
\hline IVE & 18,50 & 18,20 & 18,50 & 19,85 & 20,61 & 19,13 \\
\hline $\mathrm{CR}(\mathrm{cm})$ & 9,03 & 11,18 & 10,51 & 9,93 & 10,27 & 10,18 \\
\hline $\mathrm{CP}(\mathrm{cm})$ & 7,95 & 8,54 & 7,68 & 7,94 & 7,82 & 7,98 \\
\hline $\mathrm{MF}(\mathrm{g})$ & 20,68 & 20,72 & 20,24 & 21,92 & 20,24 & 20,76 \\
\hline $\operatorname{MS}(g)$ & 1,68 & 2,02 & 1,76 & 1,74 & 1,79 & 1,79 \\
\hline
\end{tabular}


Tabela 3. Comprimento de raiz (CR), das plântulas de algodão (Gossypium hirsutum L.), em função da umidade do substrato.

\begin{tabular}{ccc}
\hline \multirow{2}{*}{ Variável } & \multicolumn{2}{c}{ Umidade do substrato $(\boldsymbol{\%})$} \\
\cline { 2 - 3 } & $\mathbf{3 0}$ & $\mathbf{6 0}$ \\
\hline CR $(\mathrm{cm})$ & $10,80 \mathrm{a}$ & $9,49 \mathrm{~b}$ \\
\hline
\end{tabular}

Médias seguidas por letras diferentes na mesma linha diferem $(\mathrm{p}<0,05)$ pelo teste F.

de água pela transpiração (ECHER et al., 2010). Por se tratarem de plântulas ainda dependentes de reservas cotiledonares e obtidas em ambiente contralado, pode-se contar apenas com a primeira hipótese.

Távora e Melo (1991) descreveram que os principais mecanismos da planta para escapar do déficit hídrico são o aumento e aprofundamento da raiz, podendo ser pelo crescimento (alongamento celular) ou pelo ganho de massa seca (crescimento e aumento de espessura das paredes celulares). Mattioni et al. (2009) verificaram maior crescimento radicular de plântulas de algodão do cultivar FMT 701 na menor disponibilidade de água $(40 \%)$ em relação ás demais condições de umidade (60 e 80\%).

Os resultados de comprimento de raízes podem ser justificados devido à variação da umidade do substrato e não pelo uso do bioestimulante, já que não foi observado efeito significativo para nenhuma das variáveis (Tabela 2). Esse fato é confirmado por Baldo et al. (2009) que trabalhando com sementes de algodão da DELTA OPAL, observaram que o tratamento das sementes com o bioestimulante Stimulate ${ }^{\circledR}$ não proporcionou melhorias ao desenvolvimento das plantas. Entretanto Lana et al. (2009) afirmam que a aplicação de reguladores de crescimento nos estádios iniciais de desenvolvimento da plântula, assim como sua utilização no tratamento de sementes, pode estimular o crescimento radicular, agindo na recuperação mais acelerada das plântulas em condições desfavoráveis, tais como déficit hídrico.

O contato ou o tempo de exposição das sementes ao bioestimulante pode não ter sido suficiente em promover incrementos significativos na qualidade fisiológica das sementes de algodão, conforme relatado anteriormente. Dessa forma, há necessidade de mais estudos via tratamento de sementes em condições de laboratório e de campo para obtenção de respostas mais consistentes da produção e da viabilidade agronômica do uso de Stimulate ${ }^{\circledR}$ no tratamento de sementes de algodão. Conclui-se que o bioestimulante Stimulate ${ }^{\circledR}$, aplicado via sementes não influencia o desempenho fisiológico de sementes de algodão cultivar FMX 966. E que o comprimento de raiz é influenciado significativamente pelas condições de umidade do substrato.

\section{REFERÊNCIAS}

ALBUQUERQUE, K. A. D. et al. Desenvolvimento de mudas de alface a partir de sementes armazenadas e enriquecidas com micronutrientes e reguladores de crescimento. Bioscience Journal, Uberlândia, v. 25, n. 5, p. 56-65, 2009.
ARAGÃO, C. A.; DANTAS, B. F.; ALVES, E. Atividade amilolítica e qualidade fisiológica de sementes armazenadas de milho super doce tratadas com ácido giberélico. Revista Brasileira de Sementes, Brasília, v. 25, n. 1, p. 43-48, 2003.

ASSOCIAÇÃO BRASILEIRA DE PRODUTORES DE ALGODÃO - ABRAPA. 2014. Disponível em:<http://www.abrapa.com.br/ estatisticas/Paginas/Algodao-no-Mundo.aspx>. Acesso em: 11 jan. 2015

BALDO, R. et al. Comportamento do algodoeiro cultivar delta opal sob estresse hídrico com e sem aplicação de bioestimulante. Ciência e Agrotecnologia, Lavras, v. 33, n. spe., p 1804-1812, 2009.

BRASIL. Ministério da Agricultura, Pecuária e Abastecimento. Secretaria Nacional de Defesa Agropecuária. Regras para análise de sementes. Brasília: MAPA/ACS, 2009. 395 p.

BRASIL. Padrões para produção e comercialização de sementes de mamona. Diário Oficial da União. Brasília, DF, n. 243, 2005. Seção 1, p. 21-22.

BUCHANAN, B. B.; GRUISSEM, W.; JONES, R. L. Biochemistry \& molecular biology of plants. Rockville: American Society of Plant Physiologists, 2000. 1367 p.

CARVALHO, N. M.; NAKAGAWA, J. Sementes: ciência, tecnologia e produção. 5. ed. Jaboticabal: Funep, 2012. 590 p.

ECHER, F. R. et al. Estresse hídrico induzido por manitol em cultivares de algodão. Revista Ciência Agronômica, Fortaleza, v. 41, n. 4, p. 638-645, 2010. http://dx.doi.org/10.1590/S180666902010000400018

LANA, A. M. Q. et al. Aplicação de reguladores de crescimento na cultura do feijoeiro. Bioscience Journal, Uberlândia, v. 25, n. 1, p. 13-20, 2009.

LAUXEN, L. R.; VILLELA, F. A.; SOARES, R. C. Desempenho fisiológico de sementes de algodão tratadas com tiametoxam. Revista Brasileira de Sementes, Brasília, v. 32, n. 3, p. 61-68, 2010. http://dx.doi.org/10.1590/S0101-31222010000300007

MAGUIRE, J. B. Speed of germination-aid in selection and evaluation for seedling emergence vigor. Crop Science, Madison, v. 2, n. 2, p. 176-177, 1962. http://dx.doi.org/10.2135/cropsci1962.001118 3X000200020033x

MATTIONI, F. et al. Desempenho de sementes de algodoeiro submetidas a diferentes tipos de estresses. Revista Brasileira de Sementes, Brasília, v. 31, n. 1, p. 80-85, 2009. http://dx.doi. org/10.1590/S0101-31222009000100009

MOTERLE, L. M. et al. Efeito do biorregulador na germinação e no vigor de sementes de soja. Revista Ceres, Viçosa, v. 58, n. 5, p. 651-660, 2011.

SANTOS, C. M.; VIEIRA, E. L. Efeito de bioestimulante na germinação de sementes, vigor de plântulas e crescimento inicial do algodoeiro. Magistra, Cruz das Almas, v. 17, n. 3, p. 124-130, 2005.

SILVA, T. T. A. et al. Qualidade fisiológica de sementes de milho na presença de bioestimulantes. Ciência e Agrotecnologia, Lavras, v. 32, n. 3, p. 840-846, 2008.

TÁVORA, F. J. A. F.; MELO, F. I. Respostas de cultivares de amendoim a ciclos de deficiência hídrica: Crescimento vegetativo, reprodutivo e relações hídricas. Revista Ciência Agronômica, Fortaleza, v. 22, n. 01-02, p. 47-60, 1991.

UNIVERSIDADE FEDERAL DE VIÇOSA - UFV. SAEG: Sistema para Análises Estatísticas. Versão 9.1. Viçosa: Fundação Arthur Bernardes, 2007. 
VIEIRA, E. L.; CASTRO, P. R. C. Ação de bioestimulante na germinação de sementes, vigor de plântulas, crescimento radicular e produtividade de soja. Revista Brasileira de Sementes, Brasília, v. 23, p. 222-228, 2001.

VIEIRA E. L.; CASTRO, P. R. C. Ação de estimulante no desenvolvimento inicial de plantas de algodoeiro (Gossypium hirsutum L.). Piracicaba: Departamento de Ciências Biológicas, 2002.
ZHANG, X.; ERVIN, E. Cytokinin-containing seaweed and humic acid extracts associated with creeping bentgrass leaf cytokinins and drought resistance. Crop Science, Madison, v. 44, n. 5 , p. 1737-1745, 2004. http://dx.doi.org/10.2135/cropsci2004.1737

Recebido: 07 fev. 201 Aprovado: 12 jan. 2015 